\title{
A resolução alternativa de litígios e o acesso à justiça: A mediação do sobreendividamento
}

Alternative Dispute Resolution and Access to Justice: The Mediation of OverIndebtedness

La résolution alternative des litiges et l'accès à la justice : le cas de la médiation du surendettement

\section{Catarina Frade}

\section{OpenEdition}

\section{Journals}

Edição electrónica

URL: http://journals.openedition.org/rccs/1184

DOI: $10.4000 /$ rccs. 1184

ISSN: 2182-7435

\section{Editora}

Centro de Estudos Sociais da Universidade de Coimbra

\section{Edição impressa}

Data de publição: 1 Maio 2003

Paginação: 107-128

ISSN: 0254-1106

\section{Refêrencia eletrónica}

Catarina Frade, «A resolução alternativa de litígios e o acesso à justiça: A mediação do sobreendividamento », Revista Crítica de Ciências Sociais [Online], 65 | 2003, colocado online no dia 01 outubro 2012, criado a 01 maio 2019. URL : http://journals.openedition.org/rccs/1184 ; DOI :

$10.4000 /$ rccs. 1184

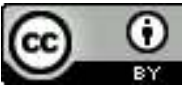




\title{
A resolução alternativa de litígios e o acesso à justiça: A mediação do sobreendividamento
}

\begin{abstract}
A consolidação das formas de resolução alternativa de litígios no quadro de um sistema fortemente marcado pela supremacia dos tribunais como instância pacificadora da conflitualidade social é uma das dinâmicas que percorrem os actuais sistemas de administração da justiça. Compreender o valor da RAL na construção do direito de acesso à justiça é o objectivo deste texto que, para o efeito, dá um relevo especial à mediação enquanto procedimento capaz de responder eficazmente aos conflitos emergentes do sobreendividamento das famílias.
\end{abstract}

\section{Introdução}

Como responder aos conflitos que emergem numa sociedade cada vez mais plural e complexa como a actual, onde se regista uma crise da justiça cível? Esta interrogação é o ponto de partida para uma breve reflexão sobre os métodos de resolução alternativa de litígios ou $\mathrm{RAL}^{1}$, em especial sobre a mediação e as suas capacidades terapêuticas no tratamento dos casos de sobreendividamento das famílias.

Essa reflexão desenvolve-se em dois momentos. No primeiro momento, faz-se uma análise do conceito de formas de resolução alternativa de litígios, das suas características principais e modelos mais divulgados, bem como do papel da RAL no actual contexto da pacificação social. Promoção do acesso ao direito e à justiça, consagração de uma resposta mais efectiva para certos domínios da conflitualidade social e desjudicialização e informalização da justiça (descongestionamento dos tribunais) são as três principais vantagens que a RAL conseguiu introduzir no sistema de administração da justiça, tornando-o mais “justo". No segundo momento, dá-se um relevo especial à mediação, articulando-a com a problemática da

\footnotetext{
1 A RAL é conhecida na doutrina e no direito anglo-saxónicos por Alternative Dispute Resolution ou ADR e, no direito francês, por Médiation, Arbitrage, Conciliation ou MAC.
} 
resolução dos problemas derivados do endividamento excessivo das famílias. Trata-se de, a partir de um estudo de caso, procurar ilustrar as virtualidades e também os limites que a resolução extrajudicial de conflitos apresenta numa área de litigação recente como é a da expansão do crédito aos consumidores, sendo certo que este continua a ser um fenómeno cuja expressão é ainda desconhecida em Portugal e, por isso, não tem conseguido mobilizar suficientemente os actores sociais e, sobretudo, institucionais.

\section{A resolução alternativa de litígios: os termos do problema}

O direito não inventa nada, codifica uma visão do mundo à medida que se vai encontrando com o real.

P. Delmas, O Senhor do Tempo

\subsection{Da conflitualidade à litigiosidade: o conceito de RAL}

Todo o litígio ou disputa tem na sua génese um conflito, ou seja, um confronto entre perspectivas divergentes. O conflito exprime as diferenças em luta entre si, espelha um clima de oposição ou de hostilidade. Tem, em regra, uma carga negativa e destrutiva, de que o exemplo último é a guerra. Mas o conflito também pode ter uma dimensão positiva, no sentido de que contém a dinâmica que leva à mudança e ao avanço da sociedade e da civilização.

Nem todos os conflitos se convertem em litígios ou disputas, no sentido de serem objecto de um reconhecimento formal pelas partes e de convocarem a intervenção de um terceiro para os resolver. ${ }^{2}$ Várias razões podem impedir que um conflito se converta no objecto de um litígio. Desde logo, qualquer das partes pode não identificar o conflito enquanto tal, isto é, não o reconhecer ou não ter sequer consciência dele. Pode, por outro lado, identificá-lo, mas não formalizá-lo, na medida em que não confronta a parte contrária com ele e opta por uma atitude de resignação. Pode, finalmente, conseguir resolvê-lo directamente com a contraparte, sem que, por isso, haja lugar à intervenção de qualquer pessoa ou entidade neutra com a missão de facilitar ou sugerir a solução ou mesmo de impô-la autonomamente.

Só quando os conflitos são formalmente assumidos e exigem a intervenção de uma instância para os pacificar (assuma ela a forma de conciliação, mediação, arbitragem ou tribunal judicial), passam a designar-se por litígios. De imediato se levantam vários problemas, nomeadamente o de

\footnotetext{
${ }^{2}$ Sobre a distinção entre conflito e litígio e a natureza de cada um dos conceitos, cf. Brown e Marriott, 1999: 1-11.
} 
saber qual o meio de resolução mais adequado face à natureza do litígio, à oferta de meios disponíveis e às características sócio-jurídicas da comunidade. Este é quase sempre o ponto fulcral da análise sobre os sistemas de resolução de litígios que tem vindo a ser feita nas culturas jurídicas contemporâneas dos países ocidentais.

Assim, quando se fala de meios de resolução alternativa de litígios é necessário explicitar o sentido do termo alternativos: trata-se de meios substitutivos (por ineficiência do método tradicional da decisão judicial), concorrenciais (por disputarem o mesmo mercado conflitual) ou complementares (por responderem a novas conflitualidades sociais que são "estranhas" aos tribunais) da via judicial?

A resolução de litígios compreende duas categorias principais de processos ou modos de resolução: processos adjudicatórios e processos consensuais.

Entende-se por adjudicação o modo de resolução no qual a decisão vinculativa sobre o litígio não deriva do mandato das partes, mas da ordem jurídica a que estas estão sujeitas. O terceiro neutro e imparcial tem legitimidade para impor a sua decisão aos litigantes. Esta é a situação típica das decisões judiciais e é também a das decisões arbitrais, embora estas tenham na sua base um consenso das partes quanto à escolha do processo (convenção arbitral). ${ }^{3}$

Os processos consensuais são aqueles nos quais as partes têm o controlo do resultado e dos termos do processo. O terceiro neutro não tem poder para proferir uma decisão vinculativa das partes, apenas pode auxiliá-las no seu próprio caminho de construção da solução do litígio, com uma intervenção que pode ir do simples facilitar do contacto entre os litigantes (como acontece na conciliação) até à sugestão de medidas de acordo (como sucede na mediação).

Os meios de resolução alternativa de litígios são procedimentos de natureza consensual que funcionam como alternativa à litigação em tribunal e envolvem a intervenção de um terceiro neutro e imparcial face à contenda (Brown e Marriott,1999: 12).

\footnotetext{
${ }^{3}$ Originalmente, a arbitragem foi incluída na RAL, na medida em que esta, tal como os restantes mecanismos de RAL, representa uma alternativa à via judicial. Todavia, a tendência actual é para a integrar nos métodos de adjudicação e considerar como exemplos de RAL apenas os mecanismos de natureza consensual como a conciliação e a mediação (Brown e Marriott, 1999: 20). Em total desacordo com a exclusão da arbitragem do elenco dos meios de RAL está Mackie (1991: 17), que considera uma ironia o facto de a arbitragem ser considerada, pelo menos no domínio da actividade comercial, como uma forma de evitar a litigação judicial. A arbitragem ocupa, a meu ver, uma posição de charneira no quadro dos processos de resolução de litígios: combina aspectos de consenso, como o acordo das partes na escolha do tribunal arbitral, a celeridade, o baixo custo e maior agilidade processual, com o carácter vinculativo e unilateral da decisão, típico da adjudicação. Neste trabalho, optei por inseri-la no contexto da RAL.
} 


\subsection{Conciliação, mediação e arbitragem}

O movimento da RAL nasceu nos EUA nas décadas de sessenta e setenta do século XX. Rapidamente transpôs fronteiras e alcançou a Europa, começando pelo Reino Unido e pela Escandinávia, contagiando um número crescente de países e acabando por chegar a Portugal.

Pode dizer-se que a expansão e diversificação dos hábitos de "consumo do direito e da justiça" têm acompanhado, em termos geográficos e temporais, a expansão e diversificação do consumo dos demais bens e serviços. ${ }^{4}$ O consumo em alta dos serviços de justiça (em particular dos tribunais) não é só uma realidade convivente, mas também emergente da expansão do consumo em geral. A chamada "sociedade de consumo" tem gerado novos espaços de conflitualidade social (conflitos de consumo em sentido estrito e conflitos ligados à contratação de crédito ou de seguros de protecção ao crédito, por exemplo) que partilham da urgência e do dinamismo do contexto em que se inserem, e que nem sempre encontram nos tribunais uma resposta satisfatória.

A RAL tem permitido, entre outros aspectos, responder com vantagem à procura de soluções céleres e eficazes, nomeadamente em matéria de consumo e de crédito. Procedimentos de RAL como a conciliação e, sobretudo, a mediação e a arbitragem têm vindo a conquistar um lugar cada vez mais relevante nesta nova área de conflitualidade. ${ }^{5}$

$\mathrm{Na}$ conciliação, a intervenção de uma terceira parte, alheia ao conflito, ajuda os litigantes a encontrarem uma plataforma de acordo tendo em vista resolver a disputa. $\mathrm{Na}$ mediação, a intervenção do terceiro neutro faz-se através da apresentação às partes de uma recomendação ou proposta de acordo da sua autoria. Enquanto o conciliador se limita a pôr as partes em contacto e a facilitar a comunicação ente elas, mas sem aventar qualquer proposta de consenso, o mediador vai mais além e sugere activamente o conteúdo do acordo a celebrar pelas partes. Por isso, o controlo do processo pelas partes é maior na conciliação do que na mediação. A arbitragem representa a submissão de um litígio de facto ou de direito, ou de ambos, a um tribunal arbitral, composto por uma ou mais pessoas, ao qual as partes atribuem o poder de emitir uma decisão vinculante. $O$ árbitro decide com base no direito ou segundo juízos de equidade (Pedroso, 2001a: 75).

A par destes "clássicos" da RAL, existem hoje, sobretudo nos países anglo-saxónicos, outros procedimentos de resolução não adjudicatórios

\footnotetext{
${ }^{4}$ Sobre a expansão da sociedade de consumo e do crédito a ele associado, cf. Marques et al. (2000) e Marques e Frade (2003).

${ }^{5}$ Sobre a arbitragem de conflitos de consumo, cf. Pedroso (2001a; 2001b) e Pedroso e Cruz (2000).
} 
como a avaliação prévia independente, o tribunal multiportas, o mini-julgamento, a peritagem, o ombundsman e a mediação-arbitragem. ${ }^{6}$ Todos eles traduzem formas distintas de seleccionar o terceiro neutro e conceber o seu papel, e incorporam diferentes níveis de controlo do processo pelas partes. São quase sempre adaptações ou aperfeiçoamentos dos procedimentos de conciliação, mediação e arbitragem, que continuam, assim, a servir de inspiração às novas figuras processuais.

\subsection{O papel da RAL nas sociedades contemporâneas: a promoção do acesso à justiça}

A RAL tem merecido um acolhimento muito favorável de boa parte da doutrina. No entanto, algumas vozes críticas acusam-na de fomentar na sociedade a ideia de que o sistema judicial não tem credibilidade e evidencia obsolescência. Há também quem a rotule de "justiça de segunda classe", considerando que sua informalidade e procura do consenso não lhe conferem a legitimidade, a autoridade e o rigor jurídico dos tribunais, além de ser susceptível de conceder menor salvaguarda aos direitos das partes, nomeadamente por tender a ignorar a desigualdade que muitas vezes existe entre os litigantes e que facilita a manipulação do processo pelo litigante mais forte (Castro Jr., 2000: 10; Merry, 1989, apud Pedroso et al., 2001: 46).

Estas acusações não têm, a meu ver, fundamentos sólidos. Por um lado, a oferta de mecanismos alternativos de resolução dos conflitos vem libertar as instâncias judiciais de muitos processos de importância menor, reservando-as para o estudo e a apreciação de causas mais complexas e juridicamente mais exigentes, aumentando, deste modo, a qualidade da própria produção judicial e reforçando o papel de pacificadores sociais desempenhado pelos tribunais. Nesta perspectiva, a implementação de mecanismos de RAL é uma forma, entre outras possíveis, de aliviar a pressão sobre o sistema judicial, tornando-o mais operativo.

Por outro lado, é na menor formalidade processual e no acordo voluntário das partes que reside boa parte da mais-valia da RAL. Celeridade, informalidade, menor custo, consideração dos interesses e dos sentimentos das partes e procura de uma solução em que todos os lados ganham são características particularmente adequadas à resolução de certos litígios, (familiares, laborais, de consumo, ambientais, comerciais ou de vizinhança), onde existe uma forte presença da componente de bem-estar pessoal ou

\footnotetext{
${ }^{6}$ Brown e Marriott (1999: 17-19) identificam cerca de 15 modalidades de RAL, todas ou quase todas já postas em prática na sociedade norte-americana, embora algumas se encontrem numa fase embrionária.
} 
comunitário. Esta componente está quase sempre associada a uma rede de relações humanas de extrema complexidade ou de grande proximidade que habitualmente se pretende preservar, o que nem sempre é possível no quadro de uma solução judicial que tem por base um processo de natureza adversarial e onde a decisão é, em regra, do tipo soma-zero. ${ }^{7}$ Em abono desta ideia há também o facto de, em domínios tão relevantes como as relações internacionais ou o comércio internacional, a cultura do consenso (através da mediação e da arbitragem) preceder historicamente as práticas de resolução de conflitos judicializadas, as quais só são utilizadas em casos extremos e de conflitualidade muito grave (é o caso, por exemplo, do Tribunal Penal Internacional, reservado aos casos de crimes contra a humanidade). Na verdade, existem entre diversos espaços sociais de conflito movimentos de sinal contrário (formalização/informalização, desjudicialização/ judicialização) que reforçam a ideia de complementaridade e continuidade entre meios adjudicatórios e não adjudicatórios.

É, todavia, no desempenho crescente da RAL na construção e consolidação de um direito de acesso à justiça que se encontra um dos seus atributos mais importantes. ${ }^{8}$

$\mathrm{O}$ acesso ao direito e à justiça corresponde à garantia de efectividade dos direitos individuais e colectivos. Os nossos direitos só se tornam efectivos quando deles temos consciência e quando, perante a sua lesão ou ameaça de lesão, podemos recorrer a uma instância ou entidade à qual reconhecemos legitimidade para dirimir o conflito (Pedroso et al., 2002: 1). Disse-se anteriormente que nem sempre os conflitos são formalizados e se convertem em litígios publicamente assumidos. A propensão para a resignação que existe na sociedade portuguesa (Santos et al., 1996) faz com que apenas um número reduzido de conflitos ultrapasse a barreira do "conformismo" ou da "indiferença" para reivindicar a tutela dos direitos e interesses lesados. E desses, o número dos que chegam aos tribunais é ainda infinitamente menor.

\footnotetext{
${ }^{7}$ A decisão soma-zero (win-lose decision) é o tipo de decisão que resulta dos processos adjudicatórios como os tribunais judiciais ou arbitrais, nos quais a distinção e a distância entre os interesses das partes, entre quem ganha e quem perde é maximizada. Designa-se por decisão mini-max (win-win agreement), a decisão típica dos procedimentos consensuais como a mediação ou a conciliação, nos quais se procura maximizar, não a diferença, mas o compromisso entre as pretensões dos diferentes litigantes, de modo a minimizar ou, se possível, eliminar a distância entre quem perde e quem ganha.

${ }^{8}$ Goldberg et al. (1985: 5-7) apresentam quatro grandes objectivos para a RAL: o descongestionamento dos tribunais e redução dos custo da justiça; a promoção do acesso à justiça; a concessão de uma resolução de litígios mais efectiva (barata, rápida, justa, eficiente e satisfatória para as partes); e a capacidade de envolvimento da comunidade no processo de resolução de litígios.
} 
Tendo por referência a pirâmide de litigiosidade (Santos et al., 1996), considerada na perspectiva dos modos de resolução de litígios, verifica-se que ela possui uma base muito grande onde se encontra toda a conflitualidade social não declarada passível de emergir num dado momento, quando comparada com o topo onde se situam os litígios judicializados.

Só quando a conflitualidade potencial se converte em conflitualidade real, isto é, só quando existe da parte do lesado uma percepção do dano e quando, além disso, ele reclama a sua reparação junto do autor do mesmo é que a relação social entra verdadeiramente na base da pirâmide. Mas é preciso que a reclamação seja rejeitada e que o lesado esteja disposto a não se resignar e a procurar uma instância com credibilidade e legitimidade para a acolher e resolver o litígio. Só a atitude inconformista do lesado perante a rejeição da sua queixa pelo lesante faz desencadear os mecanismos institucionais, mais ou menos formalizados, de resolução de conflitos. E é aqui que se faz a opção fundamental quanto ao mecanismo resolutório a adoptar. É aqui que, perante as questões de adequação, custos, interrelação, expectativas e acessibilidade se pondera qual o melhor caminho para se conseguir uma solução que responda satisfatoriamente aos interesses em causa.

É neste momento que alguns autores defendem a necessidade de ser dado aconselhamento aos litigantes sobre os meios de resolução existentes, de modo a que eles possam escolher acertada e conscientemente o processo que melhor servirá os seus intentos. (Doyle, 2000: 3). Os juízes dos tribunais federais norte-americanos estão mesmo legalmente obrigados pelo Civil Justice Reform Act de 1990 e pelo Alternative Dispute Resolution Act de 1998 a aconselhar as partes sobre a via de resolução que melhor se adequa ao seu litígio, podendo até impor-lhes a mediação ou a arbitragem, frequentemente realizadas dentro do tribunal, mas fora do julgamento - os chamados court-annexed ADR ou RAL “à sombra” do tribunal.

Em Portugal, a Lei dos Julgados de Paz (Lei n..$^{\circ}$ 78/2001, de 13 de Julho) prescreve que os litigantes devem ser informados sobre a possibilidade de resolver o seu litígio através da mediação que é feita por mediadores que operam no Julgado de Paz, mas com total autonomia face aos juizes e ao julgamento. Trata-se do primeiro exemplo de mediação que decorre oficialmente dentro do tribunal, mas que é voluntária e independente do processo judicial, pois o juiz não tem poderes para obrigar as partes a aceitarem a mediação e a entrarem em acordo. Também entre nós, nos Centros de Arbitragem de Conflitos de Consumo, a fase arbitral propriamente dita é antecedida por uma etapa de mediação voluntária, na qual se procura pôr fim ao litígio de forma mais consensual. 
Todavia, a questão do acesso à justiça começa muito antes deste problema de escolha do meio mais adequado. Ela coloca-se precisamente na passagem da conflitualidade potencial a conflitualidade real publicamente assumida e que apela à intervenção de uma qualquer instância com capacidade para solucionar o litígio. Ou seja, o problema do acesso é o problema da conversão de um conflito em litígio, para retomar a distinção conceptual feita no início. De acordo com Santos et al. (1996), na origem da resignação e da baixa propensão para litigar da sociedade portuguesa estão diversos factores económicos, sociais, culturais e até psicológicos. A recusa em litigar tanto pode ser motivada pela escassez de meios financeiros para pagar os serviços de um bom advogado como pode resultar da descrença numa efectiva reparação, como, ainda, significar uma fuga a um processo estigmatizante e emocionalmente muito penalizador.

Os processos de RAL, pelas suas características de informalização, procura do acordo, celeridade, custo tendencialmente mais reduzido e menor estigmatização pessoal e social, são procedimentos favoráveis a uma maior procura de tutela jurídica por parte de cidadãos que não se revêem no modelo clássico dos tribunais e que acabam por não reagir perante as agressões aos seus direitos. ${ }^{9}$ Por isso, ao garantir o acesso à justiça, a RAL contribui para o reforço da cidadania e do Estado democrático. ${ }^{10}$

Não pode, contudo, ignorar-se que estes mecanismos alternativos também possuem alguns aspectos negativos. Podem servir, por exemplo, para as partes medirem a força da sua pretensão tendo em vista uma ida futura a tribunal; podem ser utilizados por uma parte como um expediente dilatório, sem que haja qualquer vontade de chegar a acordo com a contraparte; podem ser uma fonte acrescida de custos quando não se alcança o consenso; e as partes podem contentar-se com menos do que aquilo a que teriam legalmente direito e que poderiam obter eventualmente numa decisão judicial. Todavia, a forma como eles são implementados, sobretudo pelo terceiro neutro, pode ajudar a contornar ou minorar todos ou quase todos estes obstáculos.

Torna-se, assim, claro que a RAL desempenha uma missão paradoxal no contexto do sistema de justiça das sociedades actuais: por um lado, contribui para o descongestionamento do sistema judicial, chamando a si uma parte da conflitualidade social que não justifica uma solução do tipo adjudicatório ou que não encaixa satisfatoriamente nos seus trâmites (desjudi-

\footnotetext{
9 Em defesa da RAL como instrumento de concretização de tutela jurídica para a conflitualidade suprimida em matéria ambiental, cf. Pureza, Frade e Dias (1997).

${ }_{10}$ Sobre o acesso à justiça em Portugal, cf. Pedroso et al., 2002.
} 
cialização e informalização da vida social); ${ }^{11}$ por outro, fomenta o aumento da litigiosidade, ao expandir a procura de tutela jurídica por parte de novos litigantes e de novas categorias de litígios - os que exprimem as novidades no panorama dos conflitos sociais e os que provêem de uma procura de tutela que até aí se encontrava suprimida por nunca chegar aos tribunais. A realização desta dupla tarefa ilustra bem que os procedimentos de RAL não vêm substituir a função adjudicatória por uma função consensual. Apenas se apresentam como mecanismos que, nuns casos, concorrem e, noutros, complementam a actividade pacificadora dos tribunais.

Partindo do pressuposto de que a RAL se apresenta como um novo caminho para a realização do direito de acesso à justiça, que não põe em causa a validade, a necessidade e a adequação do processo judicial nem constitui uma justiça menor, dar-se-á em seguida uma atenção especial a uma das suas expressões mais divulgadas e de maior sucesso, a mediação, procurando mostrar a sua adequabilidade ao tratamento dos casos de insolvência ou sobreendividamento dos agregados familiares.

\section{A mediação dos conflitos e o sobreendividamento dos consumidores}

Tal como o bombeiro se protege do fogo, o mediador deve proteger-se das emoções, dos bumores e das paixões.

Jean-Louis Lascoux, Pratique de la médiation

\subsection{Mediação e negociação}

A mediação é o modo de resolução de litígios baseado na intervenção de uma terceira parte neutral - o mediador -, que tem por missão ajudar as partes a estabelecer um acordo que ponha fim ao seu diferendo, podendo, para o efeito, apresentar-lhes propostas e sugestões de sua iniciativa tendo em vista obter o consenso.

A mediação difere da arbitragem e da conciliação no papel que é atribuído ao terceiro. $\mathrm{O}$ árbitro analisa os factos controvertidos e toma uma decisão sobre eles, a qual tem força obrigatória para as partes. O conciliador é um mero facilitador do diálogo inter-partes, não tendo qualquer poder para decidir ou sequer sugerir uma solução. O mediador é mais comprometido e pró-activo do que o conciliador, mas menos imperativo do que o árbitro. Mesmo quando ele expressa a sua opinião sobre os méritos da questão ou

${ }_{11}$ Para uma análise mais aprofundada dos processos de desjudicialização e informalização, cf. Pedroso et al., 2001. 
quando avança com um projecto de acordo (como sucede, por exemplo, em muitas das instâncias que em vários países se ocupam da mediação dos casos de sobreendividamento), a sua posição não vincula as partes de modo nenhum. Admitir o inverso seria contrariar o próprio espírito que preside à mediação e que é o ser eminentemente consensual.

A mediação constitui, assim, uma espécie de "auto-composição assistida" dos conflitos, na medida em que é da vontade das partes que decorre a celebração do acordo e são elas quem dirige as negociações sob a orientação e auxílio do mediador (Brown e Marriott, 1999: 101). Os processos de adjudicação (judicial e arbitragem) são sempre formas hetero-compositivas de solucionar os conflitos, uma vez que a decisão do caso compete à terceira entidade, que tem o poder de a impor às partes. A negociação directa entre as partes é uma forma de auto-composição em sentido estrito, dado que as partes solucionam os seus conflitos entre si e sem ajuda de terceiros. A mediação situa-se algures entre estes pólos, embora talvez mais próxima da auto-composição típica do processo de negociação.

A negociação não constitui verdadeiramente um processo de RAL, ${ }^{12}$ na medida em que não se regista a presença de um terceiro neutro. As partes discutem directamente o seu problema e, se essa discussão for bem sucedida, levará à celebração do acordo que extinguirá o conflito. A negociação pode contar com a presença de defensores das partes (advogados ou solicitadores) ou de peritos, mas estes "vestem" o interesse e a pretensão da parte que os nomeia, pelo que a bilateralização (embora a negociação não tenha que ser um processo restrito a duas partes) se mantém. A regulação do diferendo obedece, portanto, a uma lógica auto-compositiva, como foi referido.

No entanto, a negociação é o instrumento primário da mediação e dos demais métodos de RAL. Para Madux (1999, apud Brown e Marriott, 1999: 103), a negociação é o processo utilizado para satisfazer as nossas necessidades quando existe outra pessoa que controla aquilo que pretendemos. A negociação existe porque alguém tem algo que queremos obter e pelo qual estamos dispostos a lutar.

Todos aprendemos a negociar desde muito cedo, desde o adiamento da hora de dormir até ao prolongar da saída nocturna com os amigos, da taxa de juro do crédito aos acessórios que equipam o carro novo. À medida que o tempo passa, a nossa negociação torna-se mais refinada e complexa e vamos percebendo que para obtermos alguma coisa temos de dar algo em troca.

${ }^{12}$ Embora alguns autores a considerem como tal (cf. Doyle, 2000; Vasconcelos-Sousa, 2002). 
O domínio das técnicas de negociação, que possui uma forte componente de experiência, é fundamental num mediador. Só assim ele conseguirá identificar zonas de entendimento (zones of agreement) que servem de parâmetro para um possível acordo, atendendo às pretensões e às aspirações de cada litigante.

\subsection{As etapas da mediação}

Apesar de a mediação ser mais informal do que a resolução de litígios em tribunal, isso não significa que não haja um mínimo de formalidades a cumprir. De facto, a mediação não deve ser vista como um procedimento totalmente informal, em que um mediador conversa amigavelmente com as partes até que estas resolvam as suas divergências e passem a trabalhar de forma pacífica.

A mediação obedece, em regra, a um conjunto de procedimentos tendo em vista a obtenção do acordo. É possível encontrar alguma constância procedimental e elementos formais comuns entre domínios muito díspares como as relações de família, os conflitos de consumo ou as relações de trabalho.

Vasconcelos-Sousa (2002: 129-136) enumera as etapas fundamentais de um processo de mediação, muito semelhantes às que se encontram descritas em Brown e Marriott (1999) e em Lascoux (2001), e que se discriminam de seguida.

A etapa preliminar da mediação serve para explicar em que consiste este procedimento, para dar a conhecer às partes o mediador e definir os termos em que a mediação vai ser conduzida. O mediador começa por se apresentar e identificar as partes, entrando de seguida na explicação do que é a finalidade da mediação e de quais são as suas regras, a saber: a presença na mediação de livre vontade e por decisão própria dos mediados, a possibilidade de as partes interromperem ou desistirem da mediação, a necessidade de actuarem de forma cordata e de aceitarem escutar o outro lado, o compromisso do mediador de conceder as mesmas oportunidades de expressão aos mediados e a sua disponibilidade para esclarecer quaisquer dúvidas sobre o funcionamento do processo, de modo a que as partes possam escolher se avançam ou não com a mediação.

No caso de elas decidirem expressamente prosseguir, o mediador pede-lhes que assinem um acordo para efectivação da mediação. Nesse acordo são definidos vários aspectos relativos ao desenrolar da mediação: os aspectos relativos à confidencialidade da informação, o compromisso das partes de não arrolarem o mediador como testemunha em eventuais processos judiciais relativos aos temas da mediação, clarificação do papel do mediador (equidistante das partes e não advogado de uma delas) e aspectos proces- 
suais (audição conjunta ou separada dos mediados, quem pode estar presente nas sessões, quando é que o mediador pode interromper ou terminar o processo, remuneração do mediador, custos da mediação).

Terminada esta etapa prévia e sendo acordado o dia, a hora e o local da mediação (de imediato ou tão breve quanto possível), esta é formalmente desencadeada e evolui ao longo de seis etapas. Uma vez estas concluídas, deverá ser possível responder com êxito a uma dupla preocupação que está subjacente a todo este processo: solucionar de modo efectivo a disputa (objectivo directo da mediação) e pacificar a relação entre as partes (objectivo indirecto da mediação).

$\mathrm{Na}$ primeira fase, o mediador irá começar por ouvir as partes, optando, para o efeito, por um de dois formatos (ou combinando-os): o formato da diplomacia itinerante ou o formato da reunião plenária. No primeiro formato, o mediador reúne-se com cada parte em separado (ou contacta-a por outro meio), a fim de colher a sua versão dos factos e conhecer a sua predisposição. No segundo formato, o mediador encontra-se com as partes em simultâneo, reunindo-as numa mesma sala e ouvindo-as na mesma altura. As variantes e combinações dos dois formatos são frequentes e podem resultar da preferência do mediador ou da sua percepção sobre as condições próprias de cada um dos casos em que intervém. No caso da audição das partes em simultâneo, é fundamental que o mediador garanta a equidade do tempo concedido e que todos oiçam sem interromper.

$\mathrm{Na}$ segunda fase, o mediador começa por fazer um resumo do que as partes argumentaram, verificando se as partes compreendem plenamente o que foi dito e corrigindo sempre que tal seja necessário. Dá início então à primeira discussão conjunta, de modo a tornar mais claras e objectivas as preocupações dos presentes. Se assim o entender, pode também dialogar com cada parte em separado.

A terceira fase é a da enumeração e organização das questões a resolver, podendo o mediador trabalhar com as partes no sentido de estabelecer uma hierarquia dessas mesmas questões e de acordar sobre os caminhos que devem ser percorridos até se alcançar a solução.

A quarta fase é a da procura de ideias para resolver as questões elencadas, a sua selecção e o esboço de um possível acordo.

A quinta fase é expressão do entendimento conseguido entre as partes e traduz-se na redacção do acordo final. Este é revisto pelas partes, lido em voz alta pelo mediador e assinado pelos mediados. Se o acordo não foi atingido, o mediador revê os progressos que foram feitos e informa as partes dos possíveis passos a tomar: nova mediação, recurso à arbitragem ou resolução do litígio em tribunal. 
Finalmente, a sexta e última fase é preenchida com as recomendações finais do mediador e as felicitações aos mediados por terem atingido o consenso, se for esse o caso.

\subsection{O mediador}

A arte da mediação consiste em não restringir o campo de pesquisa das ideias. Para se sair da dinâmica conflitual, a imaginação e a criatividade são pontos importantes. Um problema que envolve pessoas não é resolvido se estas não participarem na sua resolução e não estiverem ou não forem motivadas para o fazer. É neste cenário, por vezes duro e desfavorável, que o mediador surge como um meio (para ultrapassar o impasse), mas nunca como uma garantia de resultado.

O mediador, seja um trabalhador assalariado ou independente, deve, antes de mais, evitar identificar-se com a causa defendida por uma ou outra parte. Perante um conflito, o mediador deve saber posicionar-se relativamente aos jogos de poder, às relações de força e às estratégias de influência utilizadas pelas partes nas negociações. A independência face ao litígio e aos litigantes faz parte da essência do papel do mediador. É por isso frequente a elaboração de códigos deontológicos aplicáveis aos profissionais da mediação e de outros RAL que asseguram o cumprimento deste e de outros princípios éticos no exercício das respectivas funções. ${ }^{13}$

Mas a independência não é a única característica que um mediador deve possuir. Brown e Marriott (1999: 329) apresentam em forma de organograma aqueles que, na sua perspectiva, devem ser os requisitos de um bom mediador.

Na base deve situar-se uma sólida aquisição de conhecimentos do mediador sobre a teoria e os princípios da mediação, o papel do mediador e os processos de gestão e resolução de conflitos através da negociação e mediação. Indispensável é também a experiência no terreno, o que deve levar a que o mediador tenha a oportunidade de se exercitar através de exercícios simulados de mediação e contar com o acompanhamento dos respectivos formadores. Ética e sensibilidade são os outros dois elementos de base de um mediador profissionalmente competente. A capacidade que o mediador tem de intervir na vida dos litigantes e alterar o rumo da disputa exige que ele se conduza de forma eticamente responsável e, embora se deva distanciar o mais possível dos aspectos emocionais envolvidos, não deve ignorar os impactos que determinadas atitudes ou decisões podem implicar no plano emocional para as partes. Seguem-se outras aptidões como a

${ }^{13}$ É o caso, por exemplo, do código deontológico da Chambre Nationale d'Arbitrage et de Médiation francesa. 
racionalidade, isto é, o poder de avaliar correctamente as diferentes dimensões do conflito; a empatia, enquanto capacidade de se identificar com os interesses de ambas as partes sem, contudo, deixar de manter a distância necessária ao desempenho da sua missão; o conhecimento técnico especializado que implica que o mediador seja alguém habilitado para compreender a questão principal do conflito (uma questão jurídica, uma questão médica ou tecnológica, por exemplo); e a criatividade e a flexibilidade, que possibilitam que o mediador vislumbre possíveis soluções para lá do que as partes, demasiado envolvidas e emocionalmente comprometidas, conseguem sugerir e que perceba as nuances por que passa o processo negocial, de modo a tirar o melhor partido dos contactos entre as partes. Por fim, o equilíbrio, que é a qualidade mais crítica de um mediador, e que implica que ele seja capaz de manter uma posição equidistante face aos litigantes, a fim de não comprometer o sucesso das negociações (Brown e Marriott, 1999: 329-335).

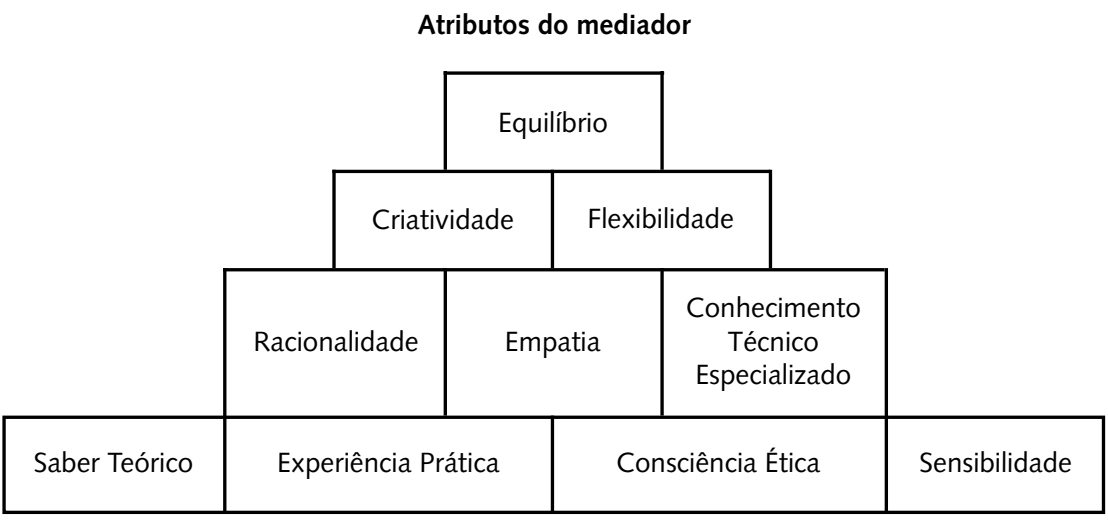

Adaptado de Brown e Marriot, 1999: 329

A somar a todas estas qualidades técnicas, os autores acrescentam ainda uma lista de atributos de natureza menos profissional e mais pessoal, a saber: compreensão da complexidade dos problemas e das preocupações e anseios das partes; intuição para apreender o que as partes não verbalizam; capacidade de conquistar e manter a confiança dos vários intervenientes, firmeza na condução e construção do processo e, finalmente, capacidade de promoção e motivação das partes através da valorização de todas as opções positivas (Brown e Marriott, 1999: 336).

A intervenção do mediador nos processos pode fazer-se com várias intensidades. Pode traduzir-se numa postura mais pró-activa - quando toma a iniciativa de avançar com uma solução possível - ou mais reactiva - quando espera que as partes lhe peçam conselhos ou sugestões. 
Diversos factores influenciam essa intensidade divergente. É o caso da formação de base e da formação específica do mediador, das suas características pessoais que ajudam a moldar um estilo próprio de mediação, da sua convicção sobre o exercício da função, da cultura dominante em cada área de litigação e do perfil dos litigantes.

Quando as partes escolhem a mediação esperam já a intervenção do mediador que virá estabelecer caminhos de diálogo e pontos de contacto. Mas a sua participação deve ser feita na medida certa, algo que só se consegue através da avaliação de cada caso e da experiência adquirida. Este é, por isso, um dos pontos onde a preparação profissional do mediador desempenha um papel essencial. O profissionalismo do mediador é um dos aspectos que mais pode contribuir para o êxito ou o fracasso de uma negociação. Estes são alguns dos aspectos que, em matéria de consumo, endividamento e sobreendividamento, são contemplados pelo Observatoire du Crédit e de l'Endettement belga nos cursos de formação de base e de formação contínua de mediadores que desde há vários anos tem vindo a ministrar. A sua experiência de mais de uma década na monitorização das questões do crédito e do endividamento das famílias e na formação de mediadores para lidar com os conflitos daí emergentes dá-nos um testemunho sólido sobre o sucesso da mediação extrajudicial e dentro do tribunal no tratamento do problema do sobreendividamento dos consumidores.

\subsection{A mediação do sobreendividamento dos consumidores - que perfil?}

\subsubsection{Sobreendividamento: um conflito que apela à mediação}

O sobreendividamento ou insolvência dos particulares, enquanto impossibilidade de o devedor fazer face às obrigações financeiras por si assumidas, é um fenómeno recente nas sociedades contemporâneas. É o produto de uma relação que tem vindo a afirmar-se cada vez com mais insistência: a relação entre consumo e crédito. As últimas décadas registaram uma profunda alteração da estrutura do consumo das famílias: com um poder de compra crescente, a oferta renovada e diversificada do comércio e dos serviços, a diminuição da taxa de poupança (que, em Portugal, e de acordo com o Banco de Portugal, era de cerca de 14\% em 1995 e de cerca de 9\% em 2001), propiciaram um consumo sistematicamente em alta. À expansão e modificação dos hábitos de consumo veio corresponder uma pulverização das formas de pagamento, com a procura de crédito ao consumo e à habitação a crescer a um ritmo bastante acelerado.

É desta combinação entre crescimento do consumo e aumento da contratação de crédito para o financiar que pode decorrer o sobreendivida- 
mento dos particulares. Este surge quando aquela relação entra em desequilíbrio devido à ocorrência de um acidente de vida de que resulta a diminuição dos rendimentos ou de uma má gestão do orçamento familiar.

A resolução dos casos de sobreendividamento representa uma conflitualidade emergente nas sociedades de consumo a crédito. A resposta a essa conflitualidade pode ser múltipla e oscilar entre uma solução de tipo judicial mais clássica e uma solução por vias extrajudiciais, nomeadamente através da mediação.

Quando se considera o caso português e a realidade dos nossos tribunais, a segunda solução parece ser a mais adequada. Sabe-se, como demonstram alguns dos estudos que têm vindo a ser conduzidos pelo Observatório Permanente da Justiça Portuguesa, que entre nós existe uma enorme resistência a litigar judicialmente. A resignação é ainda a atitude mais frequente. Reconhece-se, por outro lado, que o sistema judicial português atravessa enormes dificuldades mercê da incapacidade para responder de forma rápida e eficaz à enorme quantidade de litígios que lhe é apresentada. Além disso, o sobreendividamento é uma área de conflitualidade social ainda pouco conhecida dos tribunais e dos seus actores privilegiados: magistrados e advogados. O contexto judicial não se mostra, pois, muito favorável à recepção destes novos conflitos.

Além disso, o tipo de conflito apresenta algumas características que parecem ajustar-se melhor ao tratamento por via não judicial. Sendo o sobreendividamento um problema onde a questão temporal surge com particular acuidade (mais tempo, mais prestações em atraso, mais juros, menor capacidade de reembolso) urge optar por modelos capazes de proporcionarem uma resposta rápida e eficaz. Além disso, a escolha da mediação neste domínio vai ao encontro daquilo que é uma prática habitual na actividade das instituições financeiras: quando o devedor entra em dificuldades, quase sempre o banco se dispõe a negociar o alargamento do prazo de pagamento ou a consentir num período de jejum. Este modo de resolução é igualmente propício a uma menor penalização social e até económica do devedor insolvente, sobretudo quando ele não teve qualquer intenção de faltar ao pagamento. O devedor e o seu agregado familiar ficam menos expostos ao estigma de uma acção judicial e têm melhores condições psicológicas para tentar restabelecer o equilíbrio financeiro da família. Isso favorece a obtenção e o cumprimento do acordo que seja aprovado em sede de mediação.

É certo que nos processos de sobreendividamento existe quase sempre uma pluralidade de credores, o que torna a negociação mais complexa do que seria no caso de se tratar de uma relação bilateral. Assim, o mediador terá de saber coordenar muito bem toda a negociação inter-partes, pro- 
curando criar o consenso necessário para que seja adoptado um acordo que, em regra, neste domínio se consubstancia na aprovação de um plano escalonado de pagamentos. Naturalmente que o risco de insucesso varia na razão directa da multiplicidade de actores envolvidos.

Acresce que as relações subjacentes ao sobreendividamento registam quase sempre um grande desequilíbrio de poder entre as partes. A posição do devedor é consideravelmente mais fraca, o que tende a afectar o seu poder negocial. É por isso que, e esta é uma outra característica comum aos processos de mediação do sobreendividamento, o mediador é quase sempre levado a assumir um papel misto de mediador e defensor da parte mais débil: propõe planos de pagamento e contacta os credores para os convencer a negociar. Nas palavras de Pierre Dejemeppe,

o termo mediação não é [para este tipo de conflito] dos mais adequados, se pensarmos noutras formas de mediação como a mediação familiar. Se, neste caso, o papel do mediador é o de fazer com que as partes cheguem por si a uma solução, o mediador de dívidas é um negociador que actua a pedido do devedor. Trata-se de uma posição delicada, uma vez que, embora agindo a pedido de uma das partes, ele deve ganhar a confiança da parte contrária, no caso, o credor ou credores. (Dejemeppe, 1995)

Isso torna a posição do mediador particularmente delicada pois a sua maior proximidade com a causa do devedor pode comprometer a sua credibilidade junto dos credores. Neste ponto, a atitude, o profissionalismo e a preparação do mediador são decisivos. Normalmente, e é isso que a prática de outros países tem mostrado, o mediador consegue ganhar o respeito e a confiança dos credores que assim aceitam esse reequilíbrio de forças.

Outra dificuldade associada a este processo ocorre quando o devedor não possui bens ou rendimentos que permitam elaborar um plano amigável de pagamentos. Nestes casos, dificilmente se poderá chegar a um acordo de pagamentos e a falência judicial parece ser a única resposta possível, apesar de serem escassas as garantias de ressarcimento dos credores.

Esta é também uma área onde pode ser necessária a participação de uma equipa especializada para coadjuvar os mediadores na sua missão, onde se conte a presença, por exemplo, de juristas, trabalhadores sociais, financeiros ou psicólogos. O sobreendividamento é um fenómeno multifacetado, pois, além da questão financeira de base, existe todo um elenco de problemas psicossociais que podem surgir e dificultar a celebração do acordo. Daí que o apoio especializado possa ajudar o devedor a reabilitar-se perante si próprio e a sua família, o que sem dúvida fará aumentar a sua capacidade de cumprir 
o plano de pagamentos fixado. Um processo como a mediação tende a criar menor estigmatização social e psicológica do que uma ida a tribunal, por se tratar de um ambiente mais informal e mais resguardado, onde as partes se podem fazer ouvir e onde se consegue em menos tempo obter uma solução para o problema.

Por tudo isto, crê-se que, apostar na mediação extrajudicial - mas por que não também judicial, atendendo às potencialidades que oferecem os Julgados de Paz, com a sua mediação incorporada, se ocorrer a sua expansão territorial e o alargamento do valor das causas - reservando a tutela judicial para a fase de recurso, pode ser uma resposta ajustada a esta problemática. Deste modo, não só se pacifica a sociedade de forma menos agressiva e se favorece a manutenção das relações sociais e negociais, mas também se permite ao Estado poupar em vários domínios da despesa pública: justiça, habitação e protecção social.

\subsubsection{Algumas experiências de mediação do sobreendividamento}

Vários países europeus e não só têm vindo, com um sucesso apreciável, a aplicar a mediação extrajudicial (por vezes combinada com uma mediação dentro do tribunal e antes do julgamento, como na Bélgica) ao sobreendividamento das famílias. ${ }^{14}$ Diversas leis de tratamento do sobreendividamento impõem mesmo como condição de acesso aos tribunais a prova de que houve uma tentativa de acordo voluntário extrajudicial e de que essa tentativa falhou (é o caso das leis dinamarquesa, alemã, finlandesa, sueca, austríaca, holandesa e luxemburguesa) (Marques et al., 2000: 218-226).

No caso português, a mediação do sobreendividamento é ainda muito incipiente. A experiência mais relevante até ao momento diz respeito aos Gabinetes de Apoio e Acompanhamento ao Endividado e ao Sobreendividado criados pela Associação Portuguesa para a Defesa do Consumidor DECO, em 2000. Estes Gabinetes prestam auxílio, informação e aconselhamento a consumidores de risco que pretendam recorrer ao crédito. Acompanham também consumidores sobreendividados, ajudando-os na renegociação dos créditos e na gestão do orçamento familiar. Até meados de 2002, tinham dado entrada nos Gabinetes da DECO cerca de três centenas de processos. Segundo os seus técnicos, a renegociação com os credores mediada pela DECO foi em geral bem sucedida, embora desconheçam o grau de cumprimento dos acordos por parte dos consumidores.

\footnotetext{
${ }^{14}$ Segundo o Observatoire du Crédit e de l'Endettement, a mediação extrajudicial resolve cerca de $80 \%$ dos casos de sobreendividamento. Dos restantes que chegam a tribunal, boa parte é resolvida através da mediação realizada dentro do tribunal.
} 
A questão da mediação do sobreendividamento está a dar os primeiros passos em Portugal, necessitando de alguma atenção e reflexão, desde logo, quanto a dois aspectos. Um deles diz respeito ao facto de muitos dos sobreendividados (cujo número total é desconhecido) poderem integrar o grupo dos sobreendividados sociais, ou seja, daquelas pessoas ou famílias que nem sequer tem o mínimo necessário para sobreviver e para quem a elaboração de um plano de pagamentos é praticamente impossível. Para estes, a resposta terá de ser pensada noutros termos. Outro aspecto é o facto de, no contexto cultural e sócio-jurídico português, ser de ponderar a hipótese de uma eventual homologação judicial (através dos Julgados de Paz, se se concretizar a sua expansão territorial?) dos acordos celebrados em sede de mediação. Esta solução apenas é conhecida em França e na Bélgica (aqui só para os acordos obtidos em sede de mediação judicial). A novidade destes processos e um certo sentimento de desconfiança entre consumidores e instituições financeiras pode requerê-lo, embora esta seja uma situação que deveria ser tida por desnecessária.

A inclusão de mecanismos de RAL como a mediação terá de passar por um processo de educação e aculturação jurídica das pessoas e das instituições públicas e privadas. Terá de passar igualmente por uma aposta muito forte no apetrechamento técnico e humano das entidades capazes de fornecer serviços de mediação para estes casos e na formação cuidada, rigorosa e intensiva dos mediadores. A ideia de apostar em serviços já instalados e conhecedores da temática do consumo como os Centro de Informação Autárquicos ao Consumidor, os Centros de Arbitragem e as Associações de Defesa dos Consumidores só será praticável se existir um aumento das competências técnicas e profissionais dos seus membros. ${ }^{15}$

Os Julgados de Paz surgem como uma via potencial de resolução para estes conflitos dotada de algum interesse. De momento, e dado o valor da sua alçada (igual à alçada do tribunal de primeira instância), dificilmente poderão tratar de processos de sobreendividamento que, com grande facilidade, ultrapassam aquele valor (basta pensar no crédito à habitação, responsável por $75 \%$ do endividamento das famílias portuguesas). Uma intervenção legislativa neste ponto poderá eliminar esse obstáculo. No entanto, a mediação no quadro dos Julgados de Paz, tal como está prevista na Lei n. ${ }^{\circ} 78 / 2001$, de 13 de Julho, não é restrita às causas que podem ser conhecidas pelo tribunal, mas pode ocupar-se de outras matérias ou de causas cujo valor exceda o do Julgado. Esse facto abre a porta a processos como

${ }^{15}$ Esta ideia foi por mim defendida na proposta que apresentei ao Ministério da Justiça a propósito de um modelo de resolução extrajudicial dos casos de sobreendividamento dos consumidores (Frade, 2002). 
os de insolvência das famílias. Esta mediação fora das competências do Julgado de Paz (mas que decorre nas suas instalações), extrajudicial portanto, ainda não foi regulamentada e, nos quatro tribunais em funcionamento nesta fase experimental - Oliveira do Bairro, Seixal, Vila Nova de Gaia e Lisboa -, não é visível ainda a sua aplicação. ${ }^{16}$ Acresce que a utilidade que os Julgados de Paz podem vir a revelar nesta matéria dependerá muito da ampliação da sua rede a nível nacional.

Não se pense, pois, que a criação destes serviços é isenta de custos. A questão da sua implementação passará, entre outros aspectos, por avaliar os custos de instalação destas alternativas e os ganhos decorrentes da sua actividade face aos custos e aos ganhos associados à solução judicial.

\section{Conclusão}

Nos países anglo-saxónicos, em meados da década de setenta, os modos de resolução alternativa de litígios eram encarados como esquemas de recurso destinados a lidar com questões de importância menor ou marginal, não merecedoras de um tratamento judicial completo. Contudo, o movimento da RAL conseguiu impor-se e as suas propostas têm vindo a ganhar espaço e adeptos no terreno jurídico. Prova disso é que, além da multiplicidade de iniciativas privadas e comunitárias na área da resolução alternativa de litígios, é hoje o Estado que as acolhe quando muitos dos tribunais federais e estaduais acrescentam aos seus reportórios institucionais certos procedimentos característicos da RAL (court-annexed ADR) (Galanter, 1985 e 1993; Pedroso et al., 2001). O mesmo percurso parece estar a ser experimentado em Portugal, através da mediação associada aos Julgados de Paz e da que tem sido implementada pela DECO para os casos de sobreendividamento.

O Estado contemporâneo perdeu o monopólio da função de julgar, repartindo-a com os privados e a sociedade civil e entrando em parceria ou mesmo em concorrência com eles. Deste modo, afirma-se um novo modelo de administração da justiça, traduzido na criação de um sistema integrado de resolução de litígios que deve assentar na promoção do acesso ao direito e à justiça pelos cidadãos. Esse acesso à justiça deve ser entendido como o

\footnotetext{
${ }^{16}$ A tramitação processual dentro dos Julgados de Paz inicia-se com a apresentação do requerimento na secretaria, onde o funcionário receptor faz o primeiro atendimento. Neste momento, as partes são informadas da existência de um Serviço de Mediação, que tem por objectivo "estimular a resolução, com carácter preliminar, de litígios por acordo das partes" (art. 16. ${ }^{\circ}$ da Lei n. $\left.{ }^{\circ} 78 / 2001\right)$. Se da mediação resultar um acordo entre as partes, este será homologado pelo Juiz de Paz e terá valor de sentença. Nos casos em que a mediação for recusada, ou quando não haja lugar a acordo, o processo seguirá para audiência, onde o Juiz de Paz ouvirá as partes e promoverá a sua conciliação ou, se esta não for possível, proferirá uma decisão vinculativa.
} 
acesso à entidade (ou terceiro) que os litigantes considerem a mais legítima e a mais adequada para solucionar o seu conflito e proteger os seus direitos. Esse terceiro tanto poderá ser o tribunal como outra entidade que cumpra a mesma finalidade com eficiência e rigor (Pedroso et al., 2001: 52-53).

Esse é também o espírito que deve orientar a resolução dos problemas de sobreendividamento experimentados pelos consumidores. A necessidade de respostas céleres e adequadas ao tipo de litígio que está na base da insolvência das famílias pode passar, crê-se que com sucesso, por processos de mediação conduzidos por profissionais devidamente preparados e implementados por entidades públicas e privadas, agindo individualmente ou em parceria, mas sempre sujeitas ao mesmo rigor e controlo técnico.

\section{Referências Bibliográficas}

Brown, Henry J.; Marriott, Arthur L. (1999), ADR Principles and Practice. London: Sweet \& Maxwell.

Castro Jr., Osvaldo Agripino (2000), A Comparative Analysis of the ADR in the U.S and Brazil and Their Impact on Social Development. Working Paper. Miami.

Dejemeppe, Pierre (1995), "La médiation des dettes", Revue do CCCR.

Doyle, Margareth (2000), Advising on ADR: The Essential Guide to Appropriate Dispute Resolution. London: Advice Services Alliance.

Frade, Catarina (2002), Proposta de um modelo de resolução extrajudicial do sobreendividamento de pessoas singulares. Coimbra: Observatório Permanente da Justiça Portuguesa/Centro de Estudos Sociais.

Galanter, Marc (1985), Reading the Landscape of Disputes: What We Know and Don't Know (and Think. We Know) about Our Allegedly Contentious and Litigious Society. Madison: Disputes Processing Research Program.

Galanter, Marc (1993), "Direito em Abundância: a actividade legislativa no Atlântico Norte”, Revista Crítica de Ciências Sociais, 36, 103-145.

Goldberg, S. B. et al. (1985), Dispute Resolution. Boston: Little Brown.

Hood, Christopher; Rothstein, Henry; Baldwin, Robert (2001), The Government of Risk. Understanding Risk Regulation Regimes. Oxford: Oxford UP.

Lascoux, Jean-Louis (2001), Pratique de la médiation. Paris: Collection Formation Permanente.

Mackie, Karl J. (1991), A Handbook of Dispute Resolution: ADR in Action. London: Routledge

Marques, Maria Manuel Leitão; Frade, Catarina (2003), "Uma sociedade aberta ao crédito", Subjudice, 24, 27-34.

Marques, Maria Manuel Leitão et al. (2000), O endividamento dos consumidores. Coimbra: Almedina. 
Pedroso, João (2001a), Entre a União Europeia e a Sociedade Portuguesa: a protecção e a resolução dos litígios dos consumidores - o caso da arbitragem de conflitos de consumo em Portugal. Coimbra: Faculdade de Economia da Universidade de Coimbra (dissertação de mestrado).

Pedroso, João (2001b), “A construção de uma justiça de proximidade: o caso dos Centros de Arbitragem de Conflitos de Consumo", Revista Crítica de Ciências Sociais, 60, 33-60.

Pedroso, João et al. (2001), Percursos da informalização e da desjudicialização - por caminhos da reforma da administração da justiça (análise comparada). Coimbra: Observatório Permanente da Justiça Portuguesa/Centro de Estudos Sociais.

Pedroso, João et al. (2002), O acesso ao direito e à justiça: um direito fundamental em questão. Coimbra: Observatório Permanente da Justiça Portuguesa/Centro de Estudos Sociais.

Pureza, José Manuel; Frade, Catarina; Dias, Cristina (1997), Tribunais, natureza e sociedade: o Direito do Ambiente em Portugal. Lisboa: Cadernos do CEJ.

Santos, Boaventura de Sousa et al. (1996), Os tribunais nas sociedades contemporâneas: o caso português. Porto: Afrontamento.

Vasconcelos-Sousa, José (2002), O que é mediação. Lisboa: Quimera. 